\title{
A role for kisspeptin in islet function
}

\author{
A. C. Hauge-Evans - C. C. Richardson - H. M. Milne • \\ M. R. Christie • S. J. Persaud • P. M. Jones
}

Received: 9 March 2006 / Accepted: 2 May 2006 / Published online: 7 July 2006

(C) Springer-Verlag 2006

\begin{abstract}
Aims/hypothesis We investigated the production of kisspeptin (KISS1) and the KISS1 receptor, GPR54, in pancreatic islets and determined the effects of exogenous kisspeptin on insulin secretion.

Methods RT-PCR and immunohistochemistry were used to detect expression of KISS1 and GPR54 mRNAs and the production of KISS1 and GPR54 in human and mouse islets and in beta (MIN6) and alpha- (alphaTC1) cell lines. The effects of KISS1 on basal and glucose-induced insulin secretion from mouse and human islets were measured in a perifusion system.

Results KISS1 and GPR54 mRNAs were both detected in human and mouse islets, and GPR54 mRNA expression was also found in the MIN6 and alphaTC1 endocrine cell lines. In sections of mouse pancreas, KISS1 and GPR54 immunoreactivities were co-localised in both beta and alpha cells within islets, but were not detected in the exocrine pancreas. Exposure of mouse and human islets to KISS1 caused a stimulation of glucose-induced $(20 \mathrm{mmol} / \mathrm{l})$ insulin secretion, but had no effect on the basal rate of secretion at a sub-stimulatory concentration of glucose $(2 \mathrm{mmol} / \mathrm{l})$. In contrast, KISS1 inhibited insulin secretion from MIN6 cells at both 2 and $20 \mathrm{mmol} / 1$ glucose. KISS1 had no significant effect on glucagon secretion from mouse islets.

Conclusions/interpretation This is the first report to show that the GPR54/KISS1 system is expressed in the endocrine
\end{abstract}

A. C. Hauge-Evans • C. C. Richardson $\cdot$ H. M. Milne •

M. R. Christie - S. J. Persaud • P. M. Jones $(\triangle)$

Beta Cell Development and Function Group,

Division of Endocrinology and Development,

School of Biomedical and Health Sciences,

King's College London,

London, UK

e-mail: peter.jones@kcl.ac.uk pancreas, where it influences beta cell secretory function. These observations suggest an important role for this system in the normal regulation of islet function.

Keywords Beta cell · GPR54 · Insulin · Islet · KISS1 ·

Kisspeptin

\section{Abbreviations}

GnRH gonadotrophin-releasing hormone

KISS1 kisspeptin

\section{Introduction}

Kisspeptins (KISS1s) are a family of peptides encoded by the KISS1 gene, of which the amidated 54 amino acid form known as kisspeptin-54 or metastin is most abundant. KISS1 was originally described as a tumour-suppressor gene in breast cancer and melanoma cell lines, where it plays a role in suppression of metastasis [1]. However, KISS1s have recently been identified as ligands for an orphan G-protein-coupled receptor, GPR54, and it is becoming clear that the hypothalamic KISS1/GPR54 system plays a crucial permissive role in controlling the onset of puberty by regulating the release of gonadotrophinreleasing hormone (GnRH) from hypothalamic neurons [2]. Recent experiments using fasted animals have further suggested an important role for KISS1 as a whole-body energy sensor, which acts to modify fertility and puberty by relaying information on nutritional status to the GnRHgonadotrophin axis [3]. The physiological function(s) of KISS1 and GPR54 are not confined to hypothalamic neurons, since both elements are also expressed abundantly in pancreas and placenta [4]. In view of the importance of 
the pancreatic beta cell as a sensor and a regulator of wholebody fuel homeostasis, we hypothesised that pancreatic KISS1/GPR54 may be present in islets of Langerhans, where it may play a local role in regulating islet function.

\section{Materials and methods}

Experimental tissues

Mouse islets were isolated by collagenase digestion of the exocrine pancreas and human islets were supplied, with appropriate ethical approval, from the King's College London Human Islet Isolation Unit [5]. MIN6 and alphaTC1 cells were maintained in culture as described previously [6], and human hepatoma HepG2 cells were a gift from R. Mitry (Liver Studies Group, King's College, London).

\section{RT-PCR}

RNA was extracted using an RNAeasy kit (Qiagen, Sussex, UK). Reverse transcription to cDNA and RT-PCR amplification were performed as described previously [6] using these primer sequences: human GPR54: sense: agtgtggaccgctgg tacgt, antisense: tacagtgcgaaggcgcgctc (product $211 \mathrm{bp}, T_{\mathrm{ann}}$ $60^{\circ} \mathrm{C}$ ); mouse Gpr54: sense: ggctccgtccaacgcttcag, antisense: tgtgcttgtggcggcagata (product $175 \mathrm{bp}, T_{\mathrm{ann}} 58^{\circ} \mathrm{C}$ ); mouse Kiss 1 sense: ttcttggcagctgctgctt, antisense: cgaag gagttccagttgtag (product: $319 \mathrm{bp}, T_{\text {ann }} 55^{\circ} \mathrm{C}$ ). Human KISSI primer sequences and conditions are described in [7]. All reactions were carried out for 40 cycles. Products were separated on agarose gels and visualised by staining with ethidium bromide $(0.5 \mu \mathrm{g} / \mathrm{ml})$.

Immunohistochemistry

Triple labelling of formalin-fixed mouse pancreas sections [8] was performed with rabbit antibodies to KISS1 or
GPR54 (Phoenix Pharmaceuticals, Karlsruhe, Germany; 1:50 dilutions) together with guinea-pig anti-insulin (ICN Biomedical, Costa Mesa, CA, USA; 1:50) and mouse monoclonal anti-glucagon (Sigma, Dorset, UK; 1:50) antibodies. KISS1 and GPR54 immunoreactivities were visualised using Envision alkaline phosphatase-labelled polymer with Fast Red substrate (DAKO, Cambridge, UK), whereas insulin and glucagon were detected by immunofluorescence with Texas Red-conjugated anti-guinea-pig IgG and FITCconjugated anti-mouse $\mathrm{IgG}$, respectively (both from Stratech, Luton, UK; 1:20 dilution).

Insulin secretion

The effects of KISS1 $(1 \mu \mathrm{mol} / \mathrm{l})$ on insulin and glucagon secretion from mouse or human islets was assessed in a temperature-controlled perifusion apparatus, essentially as described $[5,6]$. Groups of 40 islets were perifused with a physiological salt solution $\left(0.5 \mathrm{ml} / \mathrm{min}, 37^{\circ} \mathrm{C}\right)$. Samples of perifusate were taken at 2-min intervals and hormone content was measured by RIA. Insulin secretion from MIN6 cells maintained as monolayers in miocrotitre plates was assessed as described previously [6].

Statistical analysis

Statistical analysis was performed using Student's $t$-tests and $p<0.05$ was considered significant.

\section{Results}

Expression of GPR54 and KISS1 in pancreatic islets

RT-PCR analysis demonstrated the expression of GPR54 in mouse and human islets (Fig. 1). Expression of KISSI was found in two separate preparations of human islets and in MIN6 cells, generating RT-PCR products of the predicted

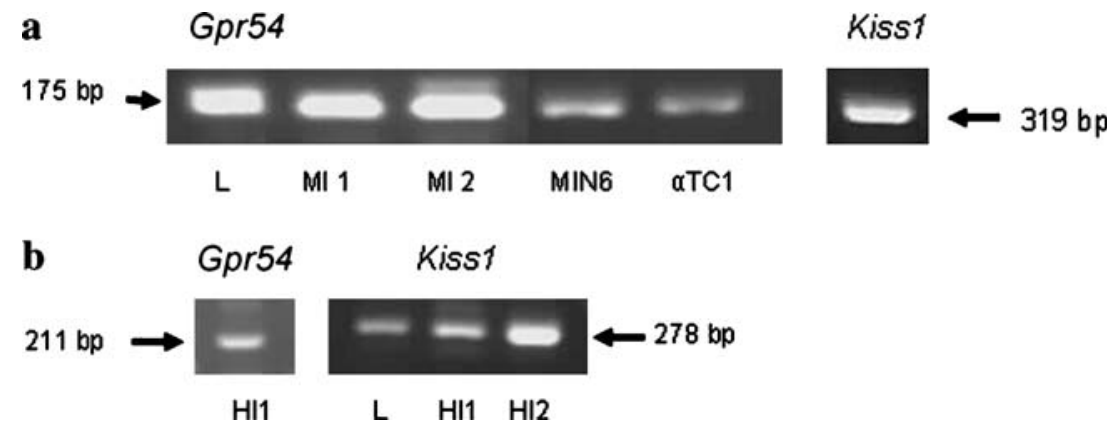

Fig. 1 KISS1 and GPR54 expression in islets of Langerhans. a Gpr54 (175 bp) and Kiss 1 (319 bp) mRNAs were detected by RT-PCR in MIN6 cell extracts. Gpr54 mRNAs were also detected in extracts of mouse liver (L), two preparations of mouse islets (MI 1 and 2) and in

the alphaTC1 cell line. b GPR54 (211 bp) and KISS1 (278 bp) mRNAs were amplified from extracts of two preparations of human islet cDNA (HI1 and 2) and HepG2 human liver cells $(L)$ 

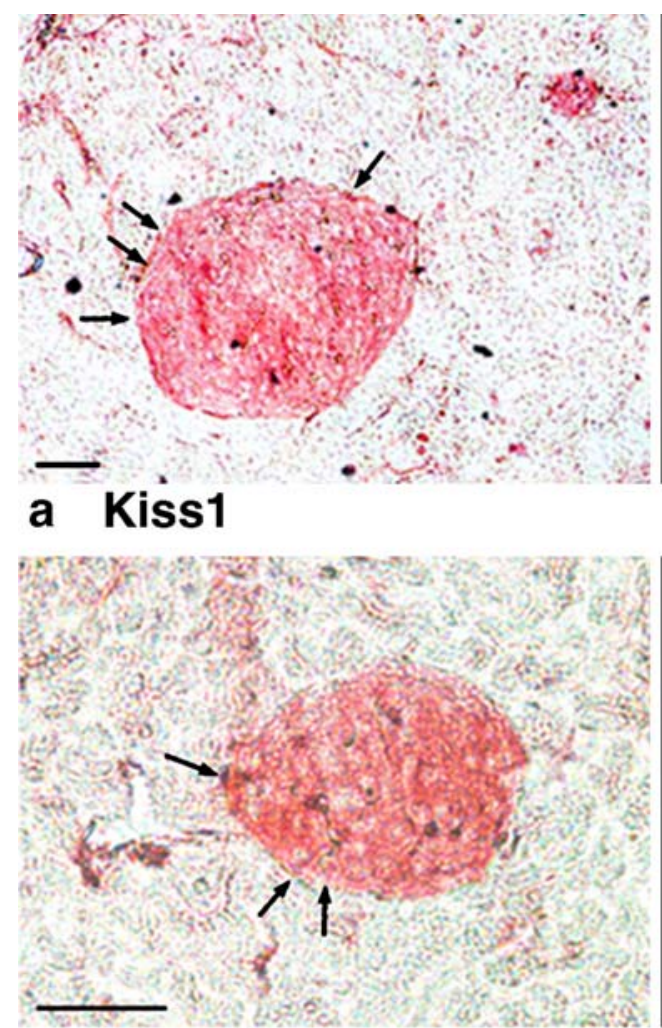

c GPR54

Fig. 2 Immunoreactive KISS1 and GPR54 in mouse pancreatic islets. Mouse pancreas sections immunolabelled for KISS1 (a) and GPR54 (c). To identify endocrine cell types expressing KISS1 and its receptor, the

size (Fig. 1b) and sequence. Expression of Gpr54 mRNA was also detected in the MIN6 mouse insulinoma cell line and in the alphaTC1 mouse glucagon-secreting cell line. These results were supported by immunostaining of mouse (Fig. 2) and human (not shown) pancreatic sections, which demonstrated that immunoreactive KISS1 and GPR54 were localised to the endocrine cells in the pancreas, with little or no immunoreactivity in the surrounding exocrine pancreas. The widespread distribution of KISS1 and GPR54 in islet cells demonstrated that most cells expressed both the peptide and its receptor (Fig. 2a,c). KISS1 and GPR54 colocalised with both insulin and glucagon immunoreactivities (Fig. 2b,d), consistent with our detection of the mRNAs in MIN6 beta cells and alphaTC1 cells.

\section{Effects of KISS1 on insulin secretion}

Exogenous KISS1 stimulated glucose-induced insulin secretion from mouse islets (Fig. 3). Increasing the glucose concentration in the perifusate from 2 to $20 \mathrm{mmol} / \mathrm{l}$ initiated a biphasic secretory response, and the presence of KISS1 induced an approximately three-fold increase $(p<0.01)$ in secretion over the stable second phase of glucose-induced

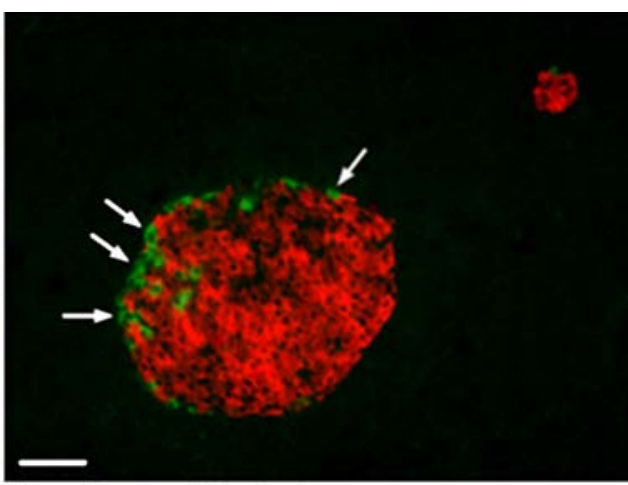

\section{b Insulin/glucagon}

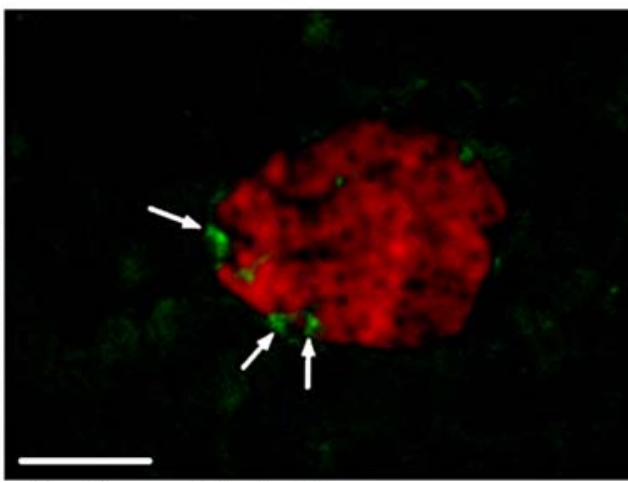

\section{d Insulin/glucagon}

same sections were co-labelled for insulin (red) and glucagon (green) by immunofluorescence $(\mathbf{b}, \mathbf{d})$. Arrows mark representative alpha cells expressing the antigens. $\mathrm{Bar}=50 \mu \mathrm{m}$

secretion. In parallel experiments, in which the glucose concentration was maintained at $2 \mathrm{mmol} / \mathrm{l}$, exposure to KISS1 had no detectable effect on insulin secretion $(p>0.2)$, although subsequent exposure to $20 \mathrm{mmol} / 1$ glucose in-

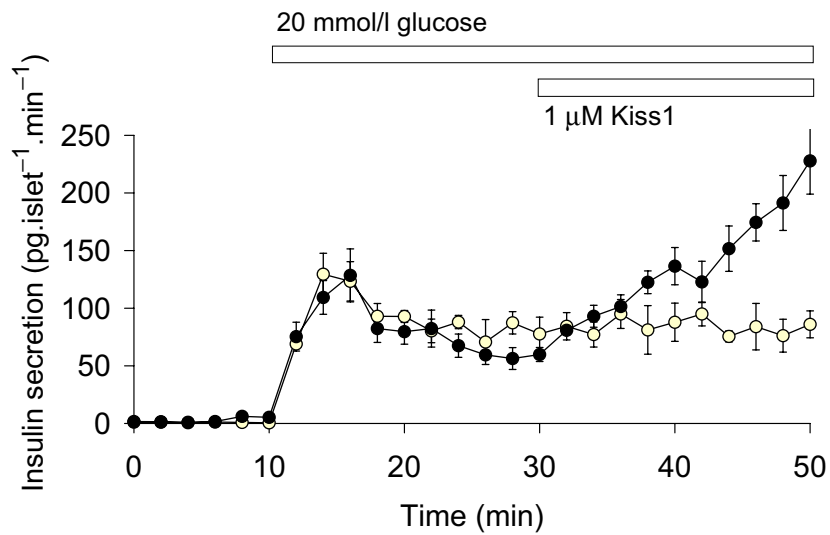

Fig. 3 Effects of KISS1 on insulin secretion. Increasing the glucose concentration from $2 \mathrm{mmol} / \mathrm{l}(0-10 \mathrm{~min}$ ) to $20 \mathrm{mmol} / \mathrm{l}$ (as shown by the bar) induced a biphasic stimulation of insulin secretion from mouse islets of Langerhans. Exposure to KISS1 ( $1 \mu \mathrm{mol} / 1$, solid symbols) caused an enhancement of the second, plateau phase of insulin secretion over that induced by glucose alone (open symbols). Points show means \pm SEM, $n=4$ 
duced a normal secretory response. KISS1 had no significant effect on glucagon secretion from mouse islets in the presence of either 2 or $20 \mathrm{mmol} / \mathrm{l}$ glucose $(2 \mathrm{mmol} / \mathrm{l}$ glucose $+1 \mu \mathrm{mol} / 1 \mathrm{KISS} 1,130 \pm 28 \%$ basal, $n=4, p>0.1$; $20 \mathrm{mmol} / 1$ glucose $+1 \mu \mathrm{mol} / 1 \mathrm{KISS} 1,129 \pm 22 \% 20 \mathrm{mmol} / 1$ glucose alone, $p>0.1$ ). In similar experiments using human islets, KISS1 ( $1 \mu \mathrm{mol} / 1)$ enhanced glucose-induced $(20 \mathrm{mmol} / \mathrm{l})$ insulin secretion by $381 \pm 71 \%($ mean \pm SEM, $n=3, p<0.01$ vs $20 \mathrm{mmol} / 1$ glucose alone). In contrast, KISS1 had small but significant inhibitory effects on insulin secretion from MIN6 cells in the presence of either $2 \mathrm{mmol} / 1$ glucose (+KISS1, $64 \pm 11 \%$ control, $p<0.05$ ) or $20 \mathrm{mmol} / 1$ glucose (+KISS1, 68 $\pm 9 \%$ control, $p<0.05$ ).

\section{Discussion}

The role of KISS1 in controlling the onset of puberty is now well established, but its role(s) in other systems remain uncertain. The pancreas contains high levels of KISS1 and its receptor [4], and our results demonstrate that this expression is confined to the endocrine islets. Both elements were expressed by the majority of islet endocrine cells, and both KP and GPR54 immunoreactivities colocalised with insulin and glucagon. The detection of both the agonist and its receptor in individual islet cells suggests an intra-islet paracrine or autocrine function, rather than a systemic function, for islet KISS1. The stimulatory effect of exogenous KISS1 on insulin secretion from mouse and human primary islets is consistent with GPR54 playing an intra-islet role in the regulation of beta cell function. The ability of KISS1 to enhance glucose-induced insulin secretion without initiating a secretory response at a substimulatory concentration of glucose is in accord with other receptor-operated beta cell agonists such as glucagon-like peptide-1, and is consistent with GPR54 being coupled to phospholipase $\mathrm{C}$ activation [4]. The lack of detectable effects of KISS1 on glucagon secretion from primary islets is consistent with a direct stimulatory effect of KISS1 on islet beta cells rather than a paracrine effect through alphacell activation, although the function of the GPR54 in alpha cells remains unclear. In direct contrast to its effects in primary beta cells, KISS1 inhibited insulin secretion from the MIN6 insulin-secreting cell line. The reasons for this disparity are unknown, but these observations emphasise the importance of using primary tissue for studies of the physiological regulation of insulin secretion, rather than relying exclusively on transformed cell lines. Measuring stimulus-induced changes in KISS1 and GPR54 expression was beyond the scope of the current study, but in other tissues gonadal steroid hormones act as negative regulators of the expression of the KISS1 and GPR54 genes [9] and this mechanism may also be operative in islets, since gonadal steroids have well-documented effects on beta cell secretory function [10].

The distribution of human GPR54 expression is tissueselective [4], and one common link between the organs that express high levels of GPR54 may be an involvement in fuel homeostasis. For example, hypothalamic studies suggest that the KISS1/GPR54 system responds to a lowered overall energy status by reducing expression of the Kiss 1 gene and thereby delaying puberty [3]. The placenta controls energy transfer from mother to fetus during pregnancy, and is a major source of circulating KISS1 with placental synthesis of KISS1s increasing as pregnancy progresses. Pancreatic beta cells also have an important role in fuel homeostasis, responding to short-term fluctuations in circulating nutrients and to longer-term changes in metabolic demand and fuel supply. Our observations suggest that KISS1/GPR54 fulfils an important intra-islet function in regulating the magnitude of insulin secretory responses to circulating nutrients.

Acknowledgements This work was supported by a grant from the Diabetes and Wellness Research Foundation. H. M. Milne was supported by a Biotechnology and Biological Sciences Research Council Committee Postgraduate Studentship. A. C. Hauge-Evans and C. C. Richardson were supported by Diabetes UK (RD04/0002905 and RD02/000244). We thank G. C. Huang and S. Amiel (King's College Hospital) for the provision of isolated human islets for the RTPCR studies, and H. Brereton for the glucagon measurements.

\section{References}

1. Lee JH, Miele ME, Hicks DJ et al (1996) KiSS-1, a novel human malignant melanoma metastasis-suppressor gene. J Natl Cancer Inst 88:1731-1737

2. Messager S, Chatzidaki EE, Ma D et al (2005) Kisspeptin directly stimulates gonadotropin-releasing hormone release via $G$ protein-coupled receptor 54. Proc Natl Acad Sci U S A 102:17611766

3. Castellano JM, Navarro VM, Fernandez-Fernandez R et al (2005) Changes in hypothalamic KiSS-1 system and restoration of pubertal activation of the reproductive axis by kisspeptin in undernutrition. Endocrinology 146:3917-3925

4. Kotani M, Detheux M, Vandenbogaerde A et al (2001) The metastasis suppressor gene KiSS-1 encodes kisspeptin, the natural ligand of the orphan $\mathrm{G}$ protein-coupled receptor GPR54. J Biol Chem 276:34631-34636

5. Huang GC, Zhao M, Jones P et al (2004) The development of new density gradient media for purifying human islets and islet-quality assessments. Transplantation 77:143-145

6. Hauge-Evans AC, Squires PE, Belin VD et al (2002) Role of adenine nucleotides in insulin secretion from MIN6 pseudoislets. Mol Cell Endocrinol 191:167-176

7. Bilban M, Ghaffari-Tabrizi N, Hintermann E et al (2004) Kisspeptin-10, a KiSS-1/metastin-derived decapeptide, is a physiological invasion inhibitor of primary human trophoblasts. J Cell Sci 117:1319-1328 
8. Roberts C, Roberts GA, Lobner K et al (2001) Expression of the protein tyrosine phosphatase-like protein IA-2 during pancreatic islet development. J Histochem Cytochem 49:767-776

9. Navarro VM, Castellano JM, Fernandez-Fernandez R et al (2004)

Developmental and hormonally regulated messenger ribonucleic acid expression of KiSS-1 and its putative receptor, GPR54, in rat hypothalamus and potent luteinizing hormone-releasing activity of KiSS-1 peptide. Endocrinology 145:4565-4574

10. Nadal A, Ropero AB, Fuentes E, Soria B, Ripoll C (2004) Estrogen and xenoestrogen actions on endocrine pancreas: from ion channel modulation to activation of nuclear function. Steroids 69:531-536 